\title{
Respiratory health effects from exposure to carbon black: results of the phase 2 and 3 cross sectional studies in the European carbon black manufacturing industry
}

\author{
K Gardiner, $M$ van Tongeren, $M$ Harrington
}

\begin{abstract}
Objectives-To assess respiratory morbidity over several cross sectional phases in the European carbon black manufacturing industry.

Methods-Participants completed an amended (and translated) MRC respiratory morbidity questionnaire with additional questions on previous exposures, job history, etc, and spirometry traces in each phase. Concurrent with the health outcome measures, personal exposure to inhalable dust was measured.

Results-Percentage participation rose from $90 \%$ in phase 2 (19 factories) to $95 \%$ in phase 3 (16 factories). Exposure dropped slightly between the 2 and 3 phases; as did the prevalence of reporting symptoms. Percentage of predicted lung function volumes exceeded $100 \%$ for forced expired volume in 1 second $\left(\mathrm{FEV}_{1}\right)$ and forced vital capacity (FVC), whereas forced mid-expiratory flow $\left(\mathbf{F E F}_{25 \%-75 \%}\right)$ and $\mathrm{FEV}_{1} / \mathrm{FVC}$ ratio were below $100 \%$ in both phases. The multiple linear and logistic regressions showed that carbon black had a significant effect on lung function and on most respiratory symptoms, respectively.

Conclusion-Both current and cumulative exposure to carbon black have a deleterious effect on respiratory morbidity. Due to the drop in exposure between phases 2 and 3, recent exposures seem to have less of an impact on the respiratory morbidity in the workers in phase 3 than those in phase 2 .

(Occup Environ Med 2001;58:496-503)
\end{abstract}

Keywords: carbon black; respiratory morbidity; spirometry

Institute of

Occupational Health, University of

Birmingham,

Birmingham B15 2TT, UK

K Gardiner

$M$ van Tongeren

$M$ Harrington

Correspondence to: Dr K Gardiner

K.Gardiner@bham.ac.uk

Accepted 17 April 2001
Carbon blacks are very fine powdered forms of elemental carbon and are manufactured by several different processes which all involve the controlled vapour phase pyrolysis of liquid or gaseous hydrocarbons. ${ }^{1}$ Currently, the oil furnace process accounts for more than $95 \%$ of world production, with most of the carbon black being used in the production of tyres. ${ }^{2}{ }^{3}$

The main concern about exposure to carbon black is the ultrafine size of the primary particle $(10-500 \mathrm{~nm})$ and their aggregates $(80-800$ $\mathrm{nm})$, although no research has been undertaken to evaluate the size distribution of the agglomerates found in occupational environments. The studies evaluating respiratory morbidity and mortality started in the early 1950s. ${ }^{4}$ Also, known carcinogenic polyaromatic hydrocarbons (PAHs) are adsorbed onto the surface of carbon black, although evidence of their bioavailability is equivocal. ${ }^{1}$ Recently, the International Agency for Research on Cancer (IARC) classified carbon black as a possible human carcinogen (2B) based on animal evidence. $^{3}$

A detailed review of the literature on the respiratory health effects of occupational exposure to carbon black has been published by Gardiner (1995). ${ }^{4} \mathrm{He}$ reported that most of the respiratory morbidity studies have either methodological shortcomings or lack the necessary detail for confident interpretation of the results. However, he concluded that exposureresponse relations were evident for small opacities on chest radiographs, forced expiratory volume in 1 second $\left(\mathrm{FEV}_{1}\right)$ and forced mid-expiratory flow $\left(\mathrm{FEF}_{25 \%-75 \%}\right)$, and the symptoms of chronic bronchitis.

Since the review by Gardiner, ${ }^{4}$ several papers have been published from studies in Germany ${ }^{5}$ and Poland..$^{7-9}$ Küpper et $a \bar{P}^{6}$ reported evidence of a relation between exposure to carbon black and lung function, albeit only among smokers, and hence a synergistic effect between smoking and exposure to dust was postulated. Szozda ${ }^{7-9}$ reported cases of hypertension and pneumoconiosis among Polish carbon black workers.

This paper describes the results of the cross sectional analyses of phases 2 and 3 of the respiratory health study of European carbon black workers. Results of the first phase of the study have already been reported. ${ }^{2}{ }^{10}$ Also, results of the exposure data from phases 2 and 3 have been reported in detail by Gardiner et $a l^{11}$ and van Tongeren et al. ${ }^{12}{ }^{13}$ Here, only the respiratory symptom and lung function results relative to exposure to inhalable carbon black dust will be described. The results presented in this paper will add to the growing body of evidence about the potential respiratory health effects of exposure to carbon black dust in particular, and of exposure to ultrafine low toxicity dusts in general. A separate paper will report on the results of the chest radiographs.

\section{Methods and materials}

STUDY DESIGN

As it was anticipated that staff turnover in this industry would be very low, it was decided that 
Table 1 The list of exposure categories, job numbers, and their respective job titles

\begin{tabular}{lll}
\hline $\begin{array}{l}\text { Exposure } \\
\text { category }\end{array}$ & fob number & fob title \\
\hline $\mathrm{S}$ & 21 & Administrative staff (office bound) \\
& 22 & Administrative staff (non-office bound) \\
$\mathrm{T}$ & 23 & Laboratory assistant \\
& 24 & Process control room operator \\
$\mathrm{U}$ & 25 & Instrument mechanic \\
$\mathrm{V}$ & 26 & Electrician \\
$\mathrm{W}$ & 27 & Process foreman \\
$\mathrm{X}$ & 28 & Furnace operator \\
$\mathrm{Y}$ & 29 & Fitter \\
& 30 & Welder \\
& 31 & Process operator \\
$\mathrm{Z}$ & 32 & Conveyor operator \\
& $33 \mathrm{a}$ & General warehouseman (for those factories using job rotation) \\
& $33 \mathrm{c}$ & Bag packers (25 kg and "big bags") \\
\hline & $33 \mathrm{~d}$ & Bulk loaders \\
& 34 & Forklift truck drivers \\
\end{tabular}

the most appropriate design would be to collect both the exposure and health outcome data concurrently over the period of a year (a phase) every 3 years for between three and four phases. All phases combined would then constitute a prospective longitudinal study. The timing of the phases is as follows: phase 1 (1987-9), phase 2 (1991-2), and phase 3 (1994-5).

POPULATION

The participating factories were in seven European countries: Great Britain $(n=2)$; France $(n=3)$; Germany $(n=5)$; Holland $(n=2)$; Italy $(n=3)$; Spain $(n=3)$; and Sweden $(n=1)$. There is a range of factory size from about 50 to 800 employees, with all but one factory below 225 employees.

People of either sex with current full time employment for more than 1 month were eligible to participate in the study. Eligible subjects were identified by the factory coordinator from personnel records. Temporary and part time employees as well as contractors (even if on site permanently) were ineligible for participation. New employees entering the factory during the period of data collection were eligible for inclusion after 1 month of employment dependent on meeting the above criteria. All eligible subjects were requested to complete a study registration form, which provided demographic data, and, if they agreed to participate in the study, asked to sign a consent form. All workers were grouped into one of 14 job titles, which were amalgamated into eight exposure categories (table 1).
SYMPTOMS

All participants completed self administered questionnaires to determine prevalence of respiratory and other symptoms. This questionnaire was based on the 1986 British Medical Research Council's questionnaire with additional questions on cardiac symptoms and skin disease. Before its use, the questionnaire was translated into the local language and then back translated to ensure correctness of meaning. Also, the questionnaire was used to collect a detailed occupational history and data on smoking habits, previous illnesses, and past exposure to respiratory hazards. After completion, the questionnaires were collected and checked only for completeness and logic by the occupational physician or nurse. Extensive checks were carried out into the consistency between the data from phases 2 and 3. In case of inconsistencies - for example, phase 3 never smoker, and phase 2 current smokerclarification was sought from the factory representatives.

To focus on the more important chronic obstructive pulmonary disease-type (COPDtype) symptoms, only the prevalence of cough, sputum production, cough with sputum production, and chronic bronchitis are presented in this report. The definitions of these respiratory symptoms are given in table 2 .

\section{LUNG FUNCTION MEASUREMENTS}

As in phase 1, lung function tests were carried out by the company medical officers, or their delegates, with a properly maintained Vitalograph S Model dry wedge bellows spirometer calibrated with a 11 syringe. The spirometer was calibrated by external specialists at the start of each data collection period and at 2 week intervals throughout the two surveys by trained factory personnel. The calibration traces were sent to the Institute of Occupational Health $(\mathrm{IOH})$ for verification on a continual basis. Measurements were undertaken to a strict procedure and in accordance with the criteria of the American Thoracic Society (ATS). ${ }^{14}$ At least three technically satisfactory forced expiratory manoeuvres were required, with the $\mathrm{FEV}_{1}$ and $\mathrm{FVC}$ from the best two traces being within $5 \%$. Technical acceptability of the spirometry traces was verified by one of the authors (KG). If the traces were not in accordance with the ATS criteria, ${ }^{14}$ the factory medical officer was requested to repeat the

Table 2 Definition of respiratory symptoms

\begin{tabular}{ll}
\hline Symptoms & Definition \\
\hline Cough & Answered yes to: \\
& Do you usually cough first thing in the morning in the winter? \\
or & Do you usually cough during the day, or at night, in the winter? \\
& Answered yes to: \\
Do you usually bring up any phlegm from your chest first thing in the morning in the winter? & or \\
& Do you usually bring up any phlegm from your chest during the day or at night in the winter? \\
& Both cough and sputum production as defined above \\
Both cough and sputum production and answered yes to: & Do you cough like this on most days for as much as 3 months each year? \\
Cough and sputum production & and \\
Chronic bronchitis & Do you bring up phlegm like this on most days for as much as 3 months each year? \\
&
\end{tabular}


measurement. All of the spirometry traces were also read by one of us (KG) blind to all factors relating to the worker except factory. Values for FVC, $\mathrm{FEV}_{1}$, and $\mathrm{FEF}_{25 \%-75 \%}$ were estimated directly from the traces.

Information on age, height, sex, and ethnic origin along with ambient temperature and barometric pressure at the time of the measurement were recorded. The lung function traces were read with the atmospheric temperature and pressure saturated (ATPS) scale and converted to body temperature and pressure saturated (BTPS) after data entry. Percentage of predicted lung function variables, calculated with the equations derived from the European Community for Steel and Coal, ${ }^{15}$ were used for descriptive analyses, and the multiple linear regression analyses used the actual volumes (1) for $\mathrm{FVC}$ and $\mathrm{FEV}_{1}$, flow rates (1/s) for $\mathrm{FEF}_{25 \%}$ $75 \%$ and percentages for the $\mathrm{FEV}_{1} / \mathrm{FVC}$ ratio; with factory, age, height, and cumulative smoking included in the models.

\section{EXPOSURE ASSESSMENT}

Personal exposure to inhalable carbon black dust was measured systematically in all participating factories. Detailed descriptions of the methods, materials, and results of the exposure measurements are given elsewhere. ${ }^{211-13}$ In summary, inhalable dust was measured with the IOM sampling head with either a Cassella AFC123 or Negretti Automation NR620 pump set at a flow rate of $2.01 . \mathrm{min}^{-1} .{ }^{16}$ Filters were conditioned in the balance room and weighed before and after sampling with a calibrated Cahn 25 automatic electrobalance. People were selected for measurement on an entirely random basis, and this random order was specified to the factory hygienists by means of a prescriptive sampling register.

To study the relation between exposure to carbon black and respiratory symptoms and lung function, two exposure metrics were used; current and cumulative exposure to inhalable dust. An estimate of the mean exposure maximum likelihood estimate based on the geometric mean and geometric standard deviation was calculated for each exposure category in each factory. ${ }^{17}{ }^{18}$ In the exposure-response analyses for current exposure, workers were assigned

Table 3 Demographic information on the population of phase 2 and phase 3, with prevalence of symptoms and percentage of predicted lung function variables

\begin{tabular}{|c|c|c|c|c|}
\hline & Phase 2 & & Phase 3 & \\
\hline Factories (n) & 19 & & 16 & \\
\hline Total population (n) & 2955 & & 2394 & \\
\hline Participants (n) & 2646 & & 2281 & \\
\hline Workers included in analyses (n) & 2324 & & 1994 & \\
\hline Age, mean (range) (y) & 41 & $(19-64)$ & 41 & $(18-64)$ \\
\hline Current smokers (\%) & 48 & & 45 & \\
\hline Ex-smokers (\%) & 27 & & 29 & \\
\hline Duration of employment (months) & 174.5 & & 177.9 & \\
\hline Current inhalable dust exposure $\left(\mathrm{mg} \cdot \mathrm{m}^{-3}\right)$ & 0.77 & & 0.57 & \\
\hline Cumulative inhalable dust exposure (mg.month. $\mathrm{m}^{-3}$ ) & 263.2 & & 245.9 & \\
\hline Prevalence of cough $(\%)$ & 14.2 & & 13.3 & \\
\hline Prevalence of sputum (\%) & 14.2 & & 11.6 & \\
\hline Prevalence of cough and sputum (\%) & 8.3 & & 7.4 & \\
\hline Prevalence of chronic bronchitis (\%) & 4.1 & & 3.7 & \\
\hline Workers with valid spirometry traces (n (\%)) & 2235 & $(96.0)$ & 1882 & $(94.4)$ \\
\hline Predicted $\mathrm{FEV}_{1}(\mathrm{SD})(\%)$ & 104.4 & $(14.5)$ & 104.1 & $(13.9)$ \\
\hline Predicted FVC (SD) (\%) & 110.4 & $(13.6)$ & 109.9 & $(13.2)$ \\
\hline Predicted $\mathrm{FEF}_{25 \%-75 \%}(\mathrm{SD})(\%)$ & 93.4 & $(30.3)$ & 92.3 & $(28.7)$ \\
\hline Predicted $\mathrm{FEV}_{1} / \mathrm{FVC}$ ratio (SD) (\%) & 90.7 & $(8.8)$ & 90.8 & $(8.1)$ \\
\hline
\end{tabular}

the mean exposure of the factory and exposure category combination. Previous analyses of phase 2 exposure data, showed that using these exposure estimates was probably the most efficient compared with other grouping schemes, as it combined limited attenuation of the hypothetical exposure-response relation towards zero (due to random measurement error) with relatively high precision of the estimated slope. ${ }^{19}$ Cumulative exposure concentrations (mg.month. $\mathrm{m}^{-3}$ ) were calculated for each person based on their job history and the mean exposure for the factory and exposure category combination in phases 1, 2, and 3. For exposure before the start of phase 1 , the phase 1 estimates were used.

STATISTICAL ANALYSES

The data were analysed with SAS for Windows release 6.12. Pulmonary function data from male Europeans were examined with multiple linear regression to provide estimates of the effect of exposure to carbon black adjusting for the effects of factory, age, height, and smoking. Data on symptoms were similarly investigated with multiple logistic regression to estimate exposure effects adjusting for factory, age, and smoking.

\section{Results}

As a result of the closure of three factories before the end of the data collection period of phase 3 and a reduction in the number of workers in the remaining factories, the total available population reduced from 2955 in phase 2 to 2394 in phase 3 (table 3). However, the participation rate increased from a mean of $90 \%$ (range $67 \%-100 \%$ ) in phase 2 to $95 \%$ (range $79 \%-100 \%$ ) in phase 3 . To assess the affect of carbon black on healthy lungs (rather than the interaction between exposure and extant lung injury or disease) all participants who reported any significant chest injuries, any operation affecting the chest, previous pulmonary tuberculosis, and all workers who had reported pleurisy or bronchial asthma before employment in the carbon black industry were excluded. Also, due to small numbers, all women and non-white people were excluded. The total number of workers available for the analyses were 2324 in phase 2 and 1994 in phase 3. Of all participants in phase 2, 1664 workers participated again in phase 3 , although 660 workers only participated in phase 2 and 330 only in phase 3 .

As a result of staff turnover the mean age of the population in both phases remained at 41 years, with a mean duration of employment of about $175-8$ months (table 3 ). The percentage of current smokers decreased from $48 \%$ in phase 2 to $45 \%$ in phase 3, with a commensurate increase in the percentage of ex-smokers from $27 \%$ to $29 \%$.

Results of the exposure measurements have been reported in detail by Gardiner et $a l^{211}$ and van Tongeren et al. ${ }^{12}{ }^{13}$ In brief, exposure has dropped considerably since the first cross sectional survey. Figure 1 presents the arithmetic mean data on exposure to inhalable dust by exposure category and phase. In phase 2 , the 


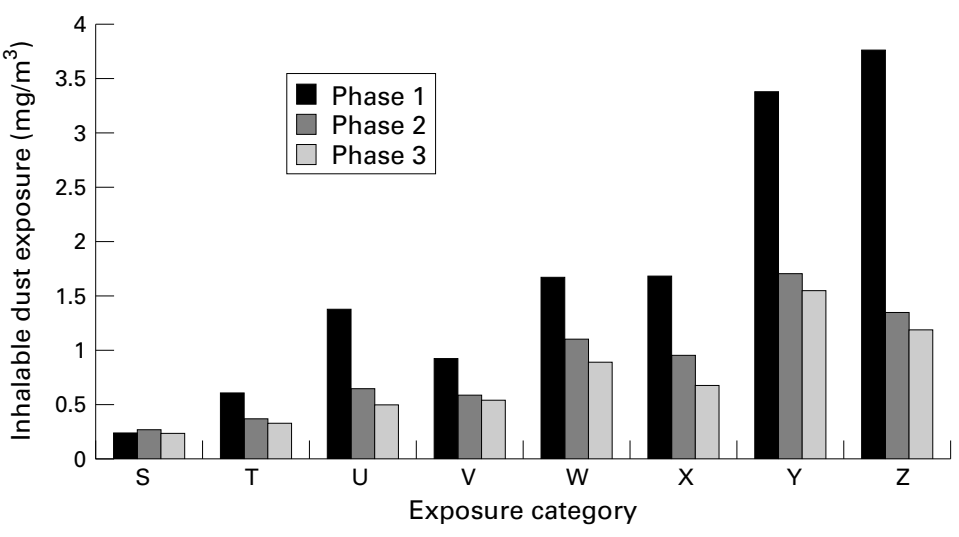

Figure 1 Arithmetic mean exposure to inhalable dust by exposure category and phase.

estimated mean current exposure to inhalable dust among the participants in the study was $0.77 \mathrm{mg} \cdot \mathrm{m}^{-3}$ (range $0.07-7.41 \mathrm{mg} \cdot \mathrm{m}^{-3}$ ), although in phase 3 this was $0.57 \mathrm{mg} \cdot \mathrm{m}^{-3}$ (range 0.11-3.26 mg. $\left.\mathrm{m}^{-3}\right)$. The drop in exposure also caused the mean cumulative exposure to decrease between the phases, even though the mean duration of employment was marginally higher in phase 3 . The mean (range) cumulative exposure to inhalable dust in phase 2 was 263.2 (0.60-3433.4) mg.month. $\mathrm{m}^{-3}$, whereas in phase 3 this was 245.9 (0.98-3506.1) mg.month. $\mathrm{m}^{-3}$.

The overall prevalence of the respiratory symptoms decreased slightly between phase 2 and phase 3 (table 3). In phase 2, 2235 (96\%) workers provided valid spirometry traces but in phase 3 this was $1882(94 \%)$. The mean percentage of predicted $\mathrm{FEV}_{1}$ and forced vital capacity (FVC) exceeded $100 \%$, whereas the percentage of predicted forced expiratory flow between $25 \%$ and $75 \%$ of expiration $\left(\mathrm{FEF}_{25 \%-}\right.$ $75 \%$ ) and the ratio of $\mathrm{FEV}_{1}$ and FVC were generally below $100 \%$ (table 3 ).
Table 4 shows the results of the logistic regressions for respiratory symptoms cough, sputum production, cough with sputum production, and chronic bronchitis using indices of exposure to inhalable dust for phases 2 and 3 . Factory, cumulative smoking, age, and current and cumulative exposure to inhalable dust were used as the independent variables. In both phases 2 and 3, significant differences were found between the factories in the prevalence for most respiratory symptoms, even after taking into account the effect of other variables. The category of cumulative smoking had a very strong effect on the prevalence of the respiratory symptoms and there were clear dose-response relations with the highest ORs found in the highest cumulative smoking groups (compared with the group of never smokers, table 4).

In phases 2 and 3, significant associations were found between the indices of exposure to inhalable dust and most respiratory symptoms (table 4). The ORs for an increase in exposure of $1 \mathrm{mg} \cdot \mathrm{m}^{-3}$ for the respiratory symptoms ranged from 1.3 to 1.4 for sputum production to 1.6 to 1.8 for chronic bronchitis. For cumulative exposure, significant ORs (for an increase in exposure of $100 \mathrm{mg} \cdot \mathrm{month} \cdot \mathrm{m}^{-3}$ ) for all respiratory symptoms were found in phase 2, although in phase 3 only ORs for cough and cough with sputum production reached significance $(\mathrm{p}<0.05)$.

To investigate whether the association between exposure to carbon black dust and respiratory symptoms was similar for smokers, ex-smokers, and never smokers, an interaction term between exposure and smoking was also included in the model. In general, there was little evidence of an interaction between smoking and exposure. Only when investigating the relation between cumulative exposure and prevalence of sputum production in phase 2

Table 4 Results of the phase 2 and 3 logistic regression models with respiratory symptom as dependent variable and factory, age, cumulative smoking, and current or cumulative exposure to inhalable dust as the independent variables

\begin{tabular}{|c|c|c|c|c|}
\hline & \multicolumn{2}{|l|}{ Phase 2} & \multicolumn{2}{|l|}{ Phase 3} \\
\hline & $\begin{array}{l}\text { Current inhalable OR } \\
(95 \% \mathrm{CI})\end{array}$ & $\begin{array}{l}\text { Cumulative inhalable } \\
\text { OR }(95 \% \text { CI) }\end{array}$ & $\begin{array}{l}\text { Current inhalable } \\
\text { OR }(95 \% \text { CI })\end{array}$ & $\begin{array}{l}\text { Cumulative inhalable } \\
\text { OR }(95 \% \text { CI) }\end{array}$ \\
\hline \multicolumn{5}{|l|}{ Cough: } \\
\hline Ex-smoker & $1.3(0.8$ to 2.2$)$ & $1.3(0.8$ to 2.2$)$ & $0.7(0.4$ to 1.2$)$ & $0.7(0.4$ to 1.2$)$ \\
\hline$\leqslant 250$ cigarette-y & $2.7(1.6$ to 4.5$)$ & $2.8(1.7$ to 4.6$)$ & $1.8(1.0$ to 3.1$)$ & $1.8(1.0$ to 3.0$)$ \\
\hline $251-500$ cigarette-y & $4.0(2.5$ to 6.6$)$ & $4.1(2.5$ to 6.7$)$ & 3.7 (2.3 to 5.9) & $3.7(2.3$ to 5.9$)$ \\
\hline$>500$ cigarette-y & $11.0(6.8$ to 17.7$)$ & 11.1 (6.9 to 17.9$)$ & $6.7(4.2$ to 10.6$)$ & 6.5 (4.1 to 10.3$)$ \\
\hline Exposure to $\mathrm{CB}^{\star}$ & $1.4(1.2$ to 1.8$)$ & $1.1(1.0$ to 1.1$)$ & $1.5(1.1$ to 2.1$)$ & $1.1(1.1$ to 1.2$)$ \\
\hline \multicolumn{5}{|l|}{ Sputum production: } \\
\hline Ex-smoker & $1.2(0.8$ to 1.9$)$ & $1.2(0.8$ to 1.9$)$ & $1.0(0.6$ to 1.7$)$ & $1.0(0.6$ to 1.7$)$ \\
\hline$\leqslant 250$ cigarette-y & $2.8(1.8$ to 4.4$)$ & $2.9(1.9$ to 4.5$)$ & $2.1(1.2$ to 3.6$)$ & $2.1(1.2$ to 3.6$)$ \\
\hline $251-500$ cigarette-y & $3.1(2.0$ to 4.8$)$ & $3.1(2.0$ to 4.9$)$ & $2.9(1.8$ to 4.8$)$ & $3.0(1.8$ to 4.9$)$ \\
\hline$>500$ cigarette-y & $5.8(3.8$ to 9.0$)$ & $5.9(3.8$ to 9.1$)$ & $5.3(3.3$ to 8.7$)$ & $5.3(3.3$ to 8.6$)$ \\
\hline Exposure to $\mathrm{CB}^{\star}$ & $1.3(1.0$ to 1.5$)$ & $1.0(1.0$ to 1.1$)$ & $1.4(1.0$ to 1.9$)$ & $1.0(1.0$ to 1.1$)$ \\
\hline \multicolumn{5}{|c|}{ Cough with sputum production: } \\
\hline Ex-smoker & $1.3(0.7$ to 2.5$)$ & $1.4(0.7$ to 2.6$)$ & $0.7(0.3$ to 1.4$)$ & $0.7(0.3$ to 1.4$)$ \\
\hline$\leqslant 250$ cigarette-y & $2.5(1.3$ to 4.8$)$ & $2.6(1.4$ to 5.0$)$ & $2.0(1.0$ to 4.0$)$ & $2.0(1.0$ to 4.0$)$ \\
\hline $251-500$ cigarette-y & $3.4(1.8$ to 6.3$)$ & $3.4(1.8$ to 6.4$)$ & $3.9(2.1$ to 7.2$)$ & 3.9 (2.1 to 7.2$)$ \\
\hline$>500$ cigarette-y & $8.3(4.6$ to 14.8$)$ & $8.5(4.8$ to 15.3$)$ & $5.6(3.1$ to 10.1$)$ & 5.4 (3.0 to 9.9$)$ \\
\hline Exposure to $\mathrm{CB}^{\star}$ & $1.5(1.2$ to 1.9$)$ & $1.1(1.0$ to 1.1$)$ & $1.6(1.0$ to 2.3$)$ & 1.1 (1.0 to 1.2$)$ \\
\hline \multicolumn{5}{|l|}{ Chronic bronchitis: } \\
\hline Ex-smoker & $0.8(0.3$ to 1.9$)$ & $0.9(0.4$ to 2.1$)$ & $1.2(0.5$ to 3.2$)$ & $1.2(0.5$ to 3.2$)$ \\
\hline$\leqslant 250$ cigarette-y & $1.6(0.7$ to 3.9$)$ & $1.7(0.7$ to 4.2$)$ & $1.4(0.4$ to 4.6$)$ & $1.4(0.4$ to 4.6$)$ \\
\hline $251-500$ cigarette-y & $2.1(0.9$ to 4.9$)$ & $2.2(1.0$ to 5.2$)$ & $4.0(1.6$ to 10.2$)$ & $4.1(1.7$ to 10.4$)$ \\
\hline$>500$ cigarette-y & $5.8(2.8$ to 12.2$)$ & $6.2(3.0$ to 12.9$)$ & $6.6(2.7$ to 15.7$)$ & 6.5 (2.7 to 15.5$)$ \\
\hline Exposure to $\mathrm{CB}^{\star}$ & $1.8(1.3$ to 2.6$)$ & $1.1(1.0$ to 1.2$)$ & $1.6(0.9$ to 2.7$)$ & $1.1(1.0$ to 1.2$)$ \\
\hline
\end{tabular}

${ }^{\star}$ ORs for carbon black (CB) exposure are given for an increase in exposure of $1 \mathrm{mg} \cdot \mathrm{m}^{-3}$ (current exposure) or $100 \mathrm{mg} \cdot \mathrm{month} \cdot \mathrm{m}^{-3}$ (cumulative exposure).

ORs $(95 \% \mathrm{CIs})$ in italic mean that these are significantly different from $1(\mathrm{p}<0.05)$. 
Table 5 Results of multiple linear regression analyses of phase 2 and 3 lung function variables as dependent and factory, age, cumulative smoking, and indices of current or cumulative exposure to dust as independent variables

\begin{tabular}{|c|c|c|c|c|}
\hline & \multicolumn{2}{|l|}{ Phase 2} & \multicolumn{2}{|l|}{ Phase 3} \\
\hline & $\begin{array}{l}\text { Current inhalable } \beta \\
(95 \% C I)\end{array}$ & $\begin{array}{l}\text { Cumulative inhalable } \beta \\
(95 \% \text { CI) }\end{array}$ & $\begin{array}{l}\text { Current inhalable } \beta \\
(95 \% \text { CI) }\end{array}$ & $\begin{array}{l}\text { Cumulative inhalable } \beta \\
(95 \% \mathrm{CI})\end{array}$ \\
\hline \multicolumn{5}{|l|}{$\mathrm{FEV}_{1}:$} \\
\hline Ex-smoker & $-0.01(-0.07$ to 0.06$)$ & $-0.01(-0.08$ to 0.06$)$ & $-0.05(-0.11$ to 0.02$)$ & $-0.05(-0.11$ to 0.02$)$ \\
\hline$\leqslant 250$ cigarette-y & $-0.06(-0.13$ to 0.01$)$ & $-0.07(-0.14$ to 0.01$)$ & $-0.06(-0.14$ to 0.02$)$ & $-0.06(-0.14$ to 0.02$)$ \\
\hline $251-500$ cigarette-y & $-0.15(-0.23$ to -0.08$)$ & $-0.16(-0.23$ to -0.08$)$ & $-0.24(-0.32$ to -0.17$)$ & $-0.25(-0.32$ to -0.17$)$ \\
\hline$>500$ cigarette-y & $-0.34(-0.42$ to -0.27$)$ & $-0.35(-0.42$ to -0.27$)$ & $-0.31(-0.39$ to -0.23$)$ & $-0.30(-0.38$ to -0.22$)$ \\
\hline Exposure to $\mathrm{CB}^{\star}$ & $-0.07(-0.11$ to -0.03$)$ & $-0.01(-0.02$ to 0.00$)$ & $-0.05(-0.10$ to 0.01$)$ & $-0.01(-0.02$ to -0.00$)$ \\
\hline \multicolumn{5}{|l|}{ FVC: } \\
\hline Ex-smoker & $0.06(-0.02$ to 0.14$)$ & $0.06(-0.02$ to 0.13$)$ & $0.01(-0.07$ to 0.09$)$ & $0.01(-0.07$ to 0.09$)$ \\
\hline$\leqslant 250$ cigarette-y & $-0.01(-0.09$ to 0.08$)$ & $-0.01(-0.09$ to 0.08$)$ & $-0.06(-0.15$ to 0.04$)$ & $-0.06(-0.15$ to 0.04$)$ \\
\hline $251-500$ cigarette-y & $0.00(-0.09$ to 0.09$)$ & $0.00(-0.09$ to 0.08$)$ & $-0.12(-0.22$ to -0.03$)$ & $-0.12(-0.22$ to -0.03$)$ \\
\hline$>500$ cigarette-y & $-0.14(-0.23$ to -0.05$)$ & $-0.14(-0.23$ to -0.05$)$ & $-0.15(-0.25$ to -0.05$)$ & $-0.15(-0.25$ to -0.05$)$ \\
\hline Exposure to $\mathrm{CB}^{\star}$ & $-0.03(-0.08$ to 0.02$)$ & $0.00(-0.01$ to 0.01$)$ & $-0.01(-0.08$ to 0.06$)$ & $0.00(-0.01$ to 0.01$)$ \\
\hline \multicolumn{5}{|l|}{$\mathrm{FEF}_{25 \%-75 \%}:$} \\
\hline Ex-smoker & $-0.16(-0.31$ to -0.01$)$ & $-0.17(-0.32$ to -0.02$)$ & $-0.23(-0.39$ to -0.08$)$ & $-0.23(-0.38$ to -0.07$)$ \\
\hline$\leqslant 250$ cigarette-y & $-0.16(-0.33$ to 0.01$)$ & $-0.18(-0.35$ to -0.01$)$ & $-0.09(-0.27$ to 0.10$)$ & $-0.09(-0.28$ to 0.09$)$ \\
\hline $251-500$ cigarette-y & $-0.56(-0.74$ to -0.38$)$ & $-0.57(-0.75$ to -0.39$)$ & $-0.60(-0.79$ to -0.42$)$ & $-0.61(-0.79$ to -0.42$)$ \\
\hline$>500$ cigarette-y & $-0.87(-1.05$ to -0.69$)$ & $-0.88(-1.06$ to -0.70$)$ & $-0.79(-0.98$ to -0.60$)$ & $-0.78(-0.97$ to -0.59$)$ \\
\hline Exposure to $\mathrm{CB}^{\star}$ & $-0.16(-0.25$ to -0.06$)$ & $-0.02(-0.04$ to -0.00$)$ & $-0.15(-0.28$ to -0.02$)$ & $-0.03(-0.05$ to -0.01$)$ \\
\hline \multicolumn{5}{|l|}{$\mathrm{FEV}_{1} / \mathrm{FVC}$ ratio: } \\
\hline Ex-smoker & $-0.99(-1.83$ to -0.14$)$ & $-1.03(-1.87$ to -0.18$)$ & $-1.08(-1.88$ to -0.28$)$ & $-1.07(-1.87$ to -0.27$)$ \\
\hline$\leqslant 250$ cigarette-y & $-1.14(-2.09$ to -0.19$)$ & $-1.23(-2.18$ to -0.28$)$ & $-0.36(-1.33$ to 0.60$)$ & $-0.38(-1.34$ to 0.58$)$ \\
\hline $251-500$ cigarette-y & $-2.70(-3.69$ to -1.72$)$ & $-2.78(-3.77$ to -1.79$)$ & $-2.78(-3.74$ to -1.82$)$ & $-2.78(-3.74$ to -1.83$)$ \\
\hline$>500$ cigarette-y & $-4.75(-5.75$ to -3.75$)$ & $-4.79(-5.80$ to -3.79$)$ & $-3.95(-4.93$ to -2.98$)$ & $-3.88(-4.85$ to -2.90$)$ \\
\hline Exposure to $\mathrm{CB}^{\star}$ & $-0.89(-1.42$ to -0.35$)$ & $-0.12(-0.23$ to -0.02$)$ & $-0.76(-1.45$ to -0.08$)$ & $-0.17(-0.28$ to -0.06$)$ \\
\hline
\end{tabular}

* Regression coefficients are given in litres $\left(\mathrm{FEV}_{1}\right.$ and $\left.\mathrm{FVC}\right), 1 . \mathrm{s}^{-1}\left(\mathrm{FEF}_{25-75}\right)$, or \% ( $\mathrm{FEV}_{1} / \mathrm{FVC}$ ratio) for an increase in exposure of $1 \mathrm{mg} . \mathrm{m}^{-3}$ (current exposure) or 100 mg.month.m ${ }^{-3}$ (cumulative exposure).

Regression coefficients (95\% CIs) in italic mean that these are significantly different from $0(p<0.05)$.

$\mathrm{CB}=$ carbon black.

and cough in phase 3 was the interaction term significant. These analyses indicated that the effect of exposure was stronger in never smokers (in the case of sputum production in phase 2 ) and ex-smokers (in the case of cough in phase 3).

Table 5 presents the results of the multiple linear regression models with lung function variables as the dependent variables and factory, cumulative smoking, age, height, and current or cumulative exposure to inhalable dust as the independent variables. As expected, age and height were strongly associated with all lung function variables. Significant differences in lung function variables (after correction for age, height, smoking, and exposure to dust) were found between the factories in both phases. Consistent significant effects are evident in the higher (medium and high) smoking groups for all lung function measures in both

Table 6 Results of exposure response analyses with both current and cumulative exposure entered simultaneously in the regression models

\begin{tabular}{|c|c|c|c|}
\hline & Exposure metric & $\begin{array}{l}\text { Phase } 2 O R^{\star} \\
\text { ( } p \text { value) }\end{array}$ & $\begin{array}{l}\text { Phase } 3 O R^{\star} \\
\text { (p value) }\end{array}$ \\
\hline \multicolumn{4}{|l|}{ Respiratory symptoms: } \\
\hline \multirow[t]{2}{*}{ Cough } & Current & $1.25 \quad(0.056)$ & $1.27 \quad(0.174)$ \\
\hline & Cumulative & $1.06(0.005)$ & $1.10(<0.001)$ \\
\hline \multirow[t]{2}{*}{ Sputum } & Current & $1.18 \quad(0.145)$ & $1.30(0.132)$ \\
\hline & Cumulative & $1.06(0.236)$ & $1.03(0.265)$ \\
\hline \multirow[t]{2}{*}{ Cough and sputum } & Current & $1.36(0.024)$ & $1.32(0.218)$ \\
\hline & Cumulative & $1.04 \quad(0.183)$ & $1.09 \quad(0.005)$ \\
\hline \multirow[t]{2}{*}{ Chronic bronchitis } & Current & $1.65(0.009)$ & $1.42(0.245)$ \\
\hline & Cumulative & $1.04 \quad(0.245)$ & $1.06(0.199)$ \\
\hline \multicolumn{2}{|l|}{ Lung function: } & $\beta+(p$ value $)$ & $\beta+(p$ value $)$ \\
\hline \multirow[t]{2}{*}{$\mathrm{FEV}_{1}$} & Current & $-0.059(0.011)$ & \\
\hline & Cumulative & $-0.004(0.382)$ & $-0.009(0.072)$ \\
\hline \multirow{2}{*}{$\mathrm{FEF}_{27 \%-75 \%}$} & Current & $-0.130(0.015)$ & $-0.103(0.142)$ \\
\hline & Cumulative & $-0.013(0.213)$ & $-0.025(0.025)$ \\
\hline \multirow[t]{2}{*}{$\mathrm{FEV}_{1} / \mathrm{FVC}$ ratio } & Current & $-0.758(0.011)$ & $-0.494(0.174)$ \\
\hline & Cumulative & $-0.065(0.265)$ & $-0.147(0.011)$ \\
\hline
\end{tabular}

${ }^{\star}$ ORs for exposure to carbon black $(\mathrm{CB})$ are given for an increase in exposure of $1 \mathrm{mg} \cdot \mathrm{m}^{-3}$ (current exposure) or $100 \mathrm{mg}$.month. $\mathrm{m}^{-3}$ (cumulative exposure).

tRegression coefficients are given in $1\left(\mathrm{FEV}_{1}\right.$ and $\left.\mathrm{FVC}\right), 1 . \mathrm{s}^{-1}\left(\mathrm{FEF}_{25-75}\right)$, or \% $\left(\mathrm{FEV}_{1} / \mathrm{FVC}\right.$ ratio for an increase in exposure of $1 \mathrm{mg} \cdot \mathrm{m}^{-3}$ (current exposure) or $100 \mathrm{mg} \cdot \mathrm{month} \cdot \mathrm{m}^{-3}$ (cumulative exposure). phases. Exposure to carbon black seems to have a consistent effect for $\mathrm{FEV}_{1}, \mathrm{FEF}_{25 \%-75 \%}$, and $\mathrm{FEV}_{1} / \mathrm{FVC}$ ratio across both phases.

Again, the effect of smoking on the exposureresponse relation was investigated by including an interaction term in the analyses. In phase 3, the interaction term was significant for $\mathrm{FEF}_{25 \%-}$ $75 \%$ and the $\mathrm{FEV}_{1} / \mathrm{FVC}$ ratio for current and cumulative exposure to dust. In general, the results of these analyses showed that the relation between exposure and decrement in $\mathrm{FEF}_{25 \%-75 \%}$ and the $\mathrm{FEV}_{1} / \mathrm{FVC}$ ratio was weakest in the group with high cumulative smoking.

As there was some correlation between the estimates of current and cumulative exposure in phase $2(r=0.4)$ and in phase $3(r=0.3)$, it was not entirely clear which of the two exposure metrics had the more important effect on respiratory morbidity. To investigate this, further exposure-response analyses were carried out in which estimates of both current and cumulative exposure were included in the model simultaneously (table 6). When reviewing the respiratory symptoms, it is evident that for cough cumulative exposure to dust is dominant in determining the prevalence, whereas for sputum production, neither current nor cumulative exposure seem to have an independent effect on the prevalence. For cough and sputum production combined, current exposure seems to be dominant in phase 2, whereas it is cumulative exposure in phase 3. Finally, for chronic bronchitis, current exposure is an independent predictor of prevalence in phase 2 , whereas in phase 3 neither current nor cumulative exposure reached significance. For the models with lung function variables, current exposure is an independent predictor of decrements in $\mathrm{FEV}_{1}, \mathrm{FEF}_{25 \%-75 \%}$ and $\mathrm{FEV}_{1} /$ FVC ratio in phase 2, but in phase 3 cumulative exposure is the more important. 


\section{Discussion}

This paper describes the results of two linked cross sectional studies designed to investigate the respiratory health of workers relative to exposure to carbon black in the European manufacturing industry. As well as the results presented here, chest radiographs were also taken from a large selection of the workforce; the results of the analyses of these radiographs will be presented elsewhere. In terms of the representative nature of the participating population, clearly $89.5 \%$ and $95.3 \%$ participation is reasonably good, although a drop in the potential population of 561, from 2955 to 2394 , is likely to introduce some bias from the effect of a survivor population.

It is thought that the comprehensive sampling strategy, which involved taking large numbers of measurements from randomly selected workers on randomly selected days, has ensured robust exposure data in terms of accuracy and precision of these estimates.

Potential problems occurred with the collection of some of the data on respiratory symptoms, as it was brought to the attention of the researchers some considerable time after the completion of the study that there were differences between the factories in the way in which the questionnaire data had been collected. In some factories, the questionnaires were self completed with the occupational physician or nurse checking the data after completion, whereas in other factories, the questionnaires were administered by the occupational physician or nurse interviewing the workers. At the start of each data collection phase, comprehensive site visits were undertaken at each factory to observe the data collection process, the equipment used, and to discuss the appropriate techniques in an attempt to ensure consistency and hence compatibility of the data. Surprisingly, no deviancies from the protocol were found or reported during the visits. However, even though the techniques used to assess respiratory morbidity are valid, internationally accepted, and were observed and reported as being used, the respiratory symptom results may have been biased, and care should be taken in the interpretation of these results. In the statistical analyses, potential differences in data collection between the factories was taken into account by including factory as a variable in the regression models.

The prevalence of most symptoms has reduced significantly since phase 1 . This reduction is due in part to the exclusion of workers in phases 2 and 3 with previous lung injuries or diseases from the analyses; the symptom prevalence is about twice as high in the workers who were excluded than in those in the analyses. However, even after allowing for this there was still a considerable reduction in the symptom prevalence. Reduction in percentage of current smokers and in exposure to dust could be the underlying cause for this decrease in prevalence.
The results presented here indicate that increased levels of exposure to carbon black are related to increased prevalence of respiratory symptoms. In phase 2, significant associations were found between exposure to carbon black dust and prevalence of all reported respiratory symptoms, and in phase 3 significant associations were found for cough and cough and sputum production. The ORs for current and cumulative exposure to inhalable dust were very similar in phase 2 and phase 3 .

As in phase 1, the percentage of predicted $\mathrm{FEV}_{1}$ and FVC were generally higher than $100 \%$, but the percentage of predicted $\mathrm{FEF}_{25 \%-}$ $75 \%$ and the $\mathrm{FEV}_{1} / \mathrm{FVC}$ ratio were below $100 \%$. The reason for this could be the very rigorous application of the ATS criteria, the result of which is to obtain the maximum possible FVC for each subject, or the fact that the reference population of Quanjer et $a l^{15}$ may not be adequate. ${ }^{20}$ Also, almost $6 \%$ of the population in phase 3 were unable to provide acceptable spirometry traces, even after many attempts. It is thought that exclusion of these workers may have biased the mean percentage of predicted lung function variables upwards.

Generally, there was a significant association between exposure and decrements in $\mathrm{FEV}_{1}$, $\mathrm{FEF}_{25 \%-75 \%}$ and the $\mathrm{FEV}_{1} / \mathrm{FVC}$ ratio in phase 2 and phase 3 , but not between exposure and decrements in FVC. The associations found between the indices of exposure to inhalable dust and decrements in the lung function variables were very similar in phase 2 and phase 3 . In the light of this consistency, it can be stated that there is clear evidence that exposure to carbon black has a detrimental effect on the lung function variables related to some obstructive effect on the middle and upper airways.

The absolute effects of an increase in current exposure of $1 \mathrm{mg} \cdot \mathrm{m}^{-3}$ and an increase in cumulative exposure of $100 \mathrm{mg}$.month. $\mathrm{m}^{-3}$ on the prevalence of respiratory symptoms and decrements in lung function were similar in phase 2 and phase 3. At the same time, the mean current exposures were lower in phase 3 than phase 2, although the mean cumulative exposure remained similar. When combining these two findings, it is evident that the influence of current exposure on respiratory morbidity in phase 3 was reduced compared with phase 2 , although the influence of cumulative exposure remained more or less the same in both phases. This was also found when both measures of current and cumulative exposure were included concurrently in the models to test the association between exposure and prevalence of symptoms or decrements in lung function variables, with current exposure being more important in phase 2, but cumulative exposure in phase 3.

Küpper et $a \bar{P}^{6}$ also found an association between decrements in lung function variables and exposure to carbon black, although this was only found among the current smokers. By contrast, inclusion of an interaction term in the analyses presented in this paper indicated that the exposure-response relation between exposure to dust was weakest among the heavy 
smokers. One explanation for this could be that the effect of exposure to dust on lung function is not large compared with that due to long term heavy smoking.

It is thought that the results presented here are more reliable than those from phase 1 for the following reasons. Firstly, contrary to phase 1 , the participation rates in phase 2 and phase 3 were sufficient to include workers from all factories in the analyses. Furthermore, the precision of the exposure estimates was much higher in phases 2 and 3 due to the increased measurements taken and the creation of new job titles and exposure categories. Also, the more appropriate maximum likelihood estimate was used for the exposure estimates, rather than the geometric mean as was the case in phase 1. Finally, in phase 1 five exposure groups were formed and the exposure indices were entered in the analyses as categorical variables, whereas in this paper continuous exposure estimates are used. Although the continuous exposure estimates assume a linear relation between exposure and response, the results are more easily interpretable. No evidence is available to suggest that this is the case, but exploration of other models - for example those including a quadratic term for exposure-did not improve the fit of the model, although a threshold effect would have some logic.

In the logistic and linear regression models, factory was a significant predictor of both the symptom prevalence and lung function variables, respectively. The reasons for this remain unclear, but could include cultural difference in reporting symptoms; differences in the means of administering the questionnaire between the factories (as mentioned previously); differences in exposure in terms of distribution of particle size (grade and production disparity); markedly variant levels of exposure before phase 1; differences in type of cigarettes; and the honesty of reporting smoking habits. Some exposures before employment in the carbon black industries were recorded and some of these variables were significantly related to symptom prevalence and lung function variables, but did not reduce the effect of factory in the models.

One other complication was that the variables factory and exposure were not independent; therefore, inclusion of the variable factory in the models affected the exposure-response relations. For respiratory symptoms, the ORs for exposure to inhalable dust generally increased after inclusion of factory, but for the lung function variables, inclusion of factory resulted in decreased exposure-response relations. The exposure-response relations were also dependent on the way inhalable exposure was estimated. In a previous paper, it was shown that some attenuation of the exposureresponse relation towards the null hypothesis occurs, due to random and non-differential misclassification of exposure. ${ }^{21}$ However, it was decided initially to use the combination of factory and exposure category as the basis for estimating personal exposure as this grouping scheme combined limited attenuation of the exposure response slope with relatively high precision. ${ }^{19}$

To set these results in context, it is important to compare them with other recent occupational studies. For the prevalence of respiratory symptoms, those found in the carbon black manufacturing industry are low compared with workers exposed to aircraft fuel or jet stream exhaust, ${ }^{22}$ organic dusts, as poultry handlers, ${ }^{23}$ welders, ${ }^{24} 25$ and several particulates (including quartz, illite, and kaolinite) in the heavy clay industry. ${ }^{26}$ For lung function measurements, this comparison between studies is difficult because most only quote percentage of predicted values, whereas it would be much easier to assess relative potency of the regression coefficients (in $1,1 / \mathrm{s}$, or the ratio) per unit of exposure to dust (1 mg.m $\mathrm{m}^{-3}$ or 100 mg.month. $\mathrm{m}^{-3}$ ).

In summary, the results presented here show that carbon black is exerting a deleterious effect on the respiratory system as assessed by means of an increase in the prevalence of symptoms such as cough and sputum production, and decrements in lung function, particularly $\mathrm{FEV}_{1}, \mathrm{FEF}_{25 \%-75 \%}$ and the $\mathrm{FEV}_{1} / \mathrm{FVC}$ ratio. The results show that an increase in exposure to inhalable dust of $1 \mathrm{mg} \cdot \mathrm{m}^{-3}$ is associated with an increase in the prevalence of respiratory symptoms of chronic bronchitis of $80 \%$ (OR $1.8,95 \%$ confidence interval $(95 \% \mathrm{CI}) 1.3$ to 2.6) in phase 2 . In phase 3 , the effect of current exposure on prevalence of chronic bronchitis was not significant, however, the prevalence of the respiratory symptoms, cough and cough and sputum production, were significantly affected by an increase in exposure of $1 \mathrm{mg} \cdot \mathrm{m}^{-3}$. Based on the estimates for cumulative exposure in phase 3, working for 40 years with a mean exposure of $1 \mathrm{mg} \cdot \mathrm{m}^{-3}$ (=480 mg.month. $\left.\mathrm{m}^{-3}\right)$, is expected to increase the prevalence of cough by almost $70 \%$ (OR 1.7, 95\% CI 1.3 to 2.1 ) and increase the prevalence of cough and sputum production by $60 \%$ (OR $1.6,95 \%$ CI 1.2 to 2.1). An increase in $1 \mathrm{mg} \cdot \mathrm{m}^{-3}$ was associated with a significant decrement in $\mathrm{FEV}_{1}$ of $70 \mathrm{ml}$ (95\% CI 30 to $110 \mathrm{ml}$ ) in phase 2 ; a decrement in $\mathrm{FEF}_{25 \%-75 \%}$ of $160 \mathrm{ml} . \mathrm{s}^{-1}$ (95\% CI 60 to 250 $\mathrm{ml} . \mathrm{s}^{-1}$ ) and $150 \mathrm{ml} . \mathrm{s}^{-1}$ (95\% CI 20 to $280 \mathrm{ml} . \mathrm{s}^{-}$ 1); and a decrement in the $\mathrm{FEV}_{1} / \mathrm{FVC}$ ratio of $0.9 \%$ (95\% CI $0.4 \%$ to $1.4 \%)$ and $0.8 \%(95 \%$ CI $0.1 \%$ to $1.5 \%$ ), in phases 2 and 3 , respectively. Again, based on the estimates for cumulative exposure to dust in phase 3 , the expected decrements after 40 years of employment with a mean exposure of $1 \mathrm{mg} \cdot \mathrm{m}^{-3}$ is 48 $\mathrm{ml}(95 \%$ CI 1 to $91 \mathrm{ml})$ for $\mathrm{FEV}_{1}, 142 \mathrm{ml} . \mathrm{s}^{-1}$ (95\% CI 43-242 ml.s ${ }^{-1}$ ) for $\mathrm{FEF}_{25 \%-75 \%}$, and $0.8 \% \quad(95 \%$ CI $0.3 \%$ to $1.3 \%)$ for the $\mathrm{FEV}_{1} / \mathrm{FVC}$ ratio. Of note; in phase 2, current exposure seems to be the most important (magnitude) exposure index relative to symptoms and lung function variables, whereas in phase 3 cumulative exposure seems to be more important. This indicates that the effects of exposure to dust on respiratory morbidity can be caused by recent high exposure levels and by long term cumulative exposure, however, it is postulated that the drop in exposure between phases 2 and 3 may have been sufficient to 
reduce it below a threshold where an acute sequalae manifests itself. If this is so, then it clearly has an impact on standard setting.

The study was sponsored by the International Carbon Black Association (ICBA). We thank the members of the Scientific Advisory Group (SAG) to the ICBA for their support and guidance. Furthermore, we thank Siromi Wijayawikrama for preparation and analyses of the dust samples, Karen Biddle and Laura Farrell for data entry, Hardeep Sandhar for management of the databases, and Julie Tucker for her assistance in the day to day running of the study.

1 Gardiner K, Hale KA, Calvert IA, et al. The suitability of the urinary metabolite 1-hydroxypyrene as an index of polynuclear aromatic hydrocarbon bioavailability from workers exposed to carbon black. Ann Occup Hyg 1992;36:681-8.

2 Gardiner K, Trethowan NW, Harrington JM, et al. Occupational exposure to carbon black in its manufacture. Ann tional exposure to carbon bla

3 IARC Monographs Working Group on the Evaluation of Carcinogenic Risks to Humans. Volume 65. Printing trades, printing inks, carbon blacks and some nitro compounds. Lyon IARC, 1995

4 Gardiner K. Effects on respiratory morbidity of occupational exposure to carbon black: a review. Arch Environ Health 1995;50:44-60.

5 Küpper HU, Breidstadt R, Ulmer WT. Pulmonary function testing among employees exposed to carbon black. Appl Occup Environ Hyg 1996;11:954-61.

6 Küpper HU, Breitstadt R, Ulmer WT. Effects on the lung function of exposure to carbon black dusts. Results of a study carried out on 677 members of staff of the DEGUSSA factory in Kalscheuren/Germany. Int Arch Occup Environ Health 1996;68:478-3.

7 Szozda R. Condition of the respiratory system in workers involved in the carbon black production. Medycyna Pracy 1994;45:57-61. (In Polish.)

8 Szozda R. The circulatory system in workers involved in Szozda R. The circulatory system in workers involved in carbon black prod

9 Szozda R. Pneumoconiosis in carbon black workers. Sangyo Ika Daigaku Zasshi 1996;18:223-8.

10 Gardiner K, Trethowan WN, Harrington JM, et al. Respiratory health effects of carbon black: a survey of European carbon black workers. Br F Ind Med 1993;50:1082-96.

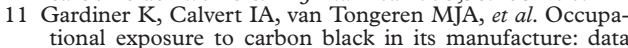
from 1987-92. Ann Occup Hyg 1996;40:65-77.
12 van Tongeren MJA, Gardiner K, Kromhout $\mathrm{H}$. Trends in levels of inhalable dust exposure, exceedance and overexposure in the European carbon black manufacturing industry. Ann Occup Hyg 2000;44:271-80.

13 van Tongeren MJA, Gardiner K. Determinants of exposure in the carbon black manufacturing industry. Appl Occup Environ Hyg 2001;16:237-45.

14 American Thoracic Society statement: standardization of spirometry: 1987 update. Am Rev Respir Dis 1987;136: 1285-98.

15 Quanjer PH, Tammeling GJ, Cotes JE, et al. Lung volumes and forced ventilatory flows. Report of the working party on standardisation of lung function tests for the European Community for Steel and Coal. Official statement of the European Respiratory Society. Eur Respir F 1993;6:5-40.

16 Mark D, Vincent JH. A new personal sampler for airborne total dust in workplaces. Ann Occup Hyg 1986;30:89-102.

17 Attfield MD, Hewitt P. Exact expressions for the bias and variance of estimators of the mean of a lognormal distribution. Am Ind Hyg Assoc f 1992;53:432-5.

18 Rappaport SM. Assessment of long-term exposures to toxic substances in air. Ann Occup Hyg 1991;35:61-121.

19 van Tongeren MJA, Gardiner K, Calvert IA, et al. Efficiency of different grouping schemes for dust exposure in the European carbon black respiratory morbidity study. Occup Environ Med 1997;54:714-19.

20 Roca J, Burgos F, Sunyer F, et al. Reference values for forced spirometry. Eur Respir f 1998;11:1354-62.

21 van Tongeren MJA, Kromhout H, Gardiner K, et al. Assessment of the sensitivity of the relationship between current exposure to carbon black and lung function parameters when using different grouping schemes. Am 7 Ind Med 1999;36:548-56.

22 Tunnicliffe WS, O'Hickey SP, Fletcher TJ, et al. Pulmonary function and respiratory symptoms in a population of airport workers. Occup Environ Med 1999;56:118-23.

23 Simpson JCG, Niven RM, Pickering CAC, et al. Prevalence and predictors of work related respiratory symptoms in workers exposed to organic dusts. Occup Environ Med 1998;55:668-72.

24 Bradshaw LM, Fishwick D, Slater T, et al. Chronic bronchitis, work-related respiratory symptoms, and pulmonary function in welders in New Zealand. Occup Environ Med 1998;55:150-4.

25 Erkinjutti-Pekkanen R, Slater T, Cheng S, et al. Two year follow up of pulmonary function values among welders in New Zealand. Occup Environ Med 1999;56:328-33.

26 Love RG, Waclawski ER, Maclaren WM, et al. Risk of respiratory disease in the heavy clay industry. Occup Environ Med 1999;56:124-33.

\section{Correspondence and editorials}

Occupational and Environmental Medicine welcomes correspondence relating to any of the material appearing in the journal. Results from preliminary or small scale studies may also be published in the correspondence column if this seems appropriate. Letters should be not more than 500 words in length and contain a minimum of references. Tables and figures should be kept to an absolute minimum. Letters are accepted on the understanding that they be subject to editorial revision and shortening.

The journal also publishes editorials which are normally specially commissioned. The Editor welcomes suggestions regarding suitable topics; those wishing to submit an editorial, however, should do so only after discussion with the Editor. 